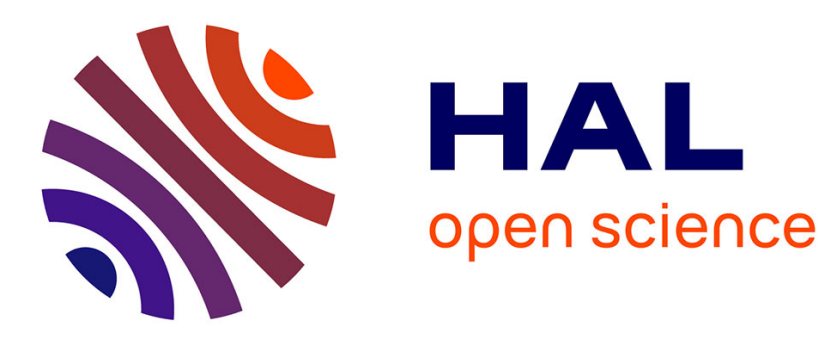

\title{
A CMOS Buried Quad p-n Junction Photodetector Model
}

Sylvain Feruglio, Thierry Courcier, Olivier Tsiakaka, Armine Karami, Annick Alexandre-Gauthier, Olivier Romain, Vincent Aimez, Paul G. Charette, Patrick Pittet, Guo-Neng Lu

\section{To cite this version:}

Sylvain Feruglio, Thierry Courcier, Olivier Tsiakaka, Armine Karami, Annick Alexandre-Gauthier, et al. A CMOS Buried Quad p-n Junction Photodetector Model. IEEE Sensors Journal, 2016, 16 (6), pp.1611-1620. 10.1109/JSEN.2015.2501347 . hal-01238701

\section{HAL Id: hal-01238701 \\ https: / hal.sorbonne-universite.fr/hal-01238701}

Submitted on 10 Dec 2015

HAL is a multi-disciplinary open access archive for the deposit and dissemination of scientific research documents, whether they are published or not. The documents may come from teaching and research institutions in France or abroad, or from public or private research centers.
L'archive ouverte pluridisciplinaire HAL, est destinée au dépôt et à la diffusion de documents scientifiques de niveau recherche, publiés ou non, émanant des établissements d'enseignement et de recherche français ou étrangers, des laboratoires publics ou privés. 


\title{
A CMOS Buried Quad p-n Junction Photodetector Model
}

\author{
S. Feruglio, Member, IEEE, T. Courcier, O. Tsiakaka, Student Member, IEEE, A. Karami, Student Member, \\ IEEE, A. Alexandre-Gauthier, O. Romain, Member, IEEE, V. Aimez, P.G. Charette, P. Pittet, G.N. Lu
}

\begin{abstract}
A buried quad junction (BQJ) photodetector has been designed and fabricated with a high-voltage CMOS process. It implements four vertically-stacked p-n junctions with four different spectral responses. This feature allows high spectral discriminating ability, greater than both conventional buried double junction and buried triple junction detectors.

In this paper, we propose a SPICE-like model, based on the physical properties of the device structure. The proposed model has been integrated in EDA software. It could be used for rapid and reliable design of system on chip, integrating the $\mathrm{BQJ}$ sensor, and its signal processing. The analytical expressions of the four BQJ photocurrents, as well as dark currents, have been developed. The spectral characteristics of the photodetector, computed with the proposed model, have been compared with those from TCAD simulations and experimental measurements. The analytical is close to the measurement with an average error on spectral responses in the range of 3-17\%, depending on the considered junction.
\end{abstract}

Index Terms-CMOS, modeling, multi-spectral sensor, optoelectronic, photodetector.

\section{INTRODUCTION}

Since the mid-twentieth century and the advent of microelectronics, the photonic devices market has been growing constantly, mainly driven by the developments of embedded systems [1]. They are now ubiquitous, simplifying our everyday life. However, there are always requirements for the detecting devices and systems to be more compact, to consume less power, to have greater sensitivity, while remaining manufacturable at low cost [2].

In the visible and near infrared (NIR) ranges, simple $p-n$ junction silicon photodiodes are extensively employed. The CMOS process has made it possible to increase the number of vertically-stacked junctions, making the detector structure have a spectral discriminating ability. This has opened the way to many applications, such as color image sensors, biochemical analyses, etc. [3-28].

This work was performed within the Labex SMART supported by French state funds managed by the ANR within the Investissements d'Avenir program under reference ANR-11-IDEX-0004-02.

S. Feruglio, O. Tsiakaka, A. Karami and A. Alexandre-Gauthier were with Sorbonne University, UPMC Univ Paris 06, CNRS UMR 7606, LIP6, F75005, Paris, France (sylvain.feruglio@upmc.fr).

O. Romain was with University of Cergy Pontoise, ENSEA, CNRS UMR 8051, ETIS, F-95004, Cergy Pontoise, France.

T. Courcier, V. Aimez and P.G. Charrette were with University of Sherbrooke, CNRS UMI-3463, LN2, Sherbrooke, Quebec J1K 2R1, Canada

P. Pittet and G.N. Lu were with UCBL University Lyon1, CNRS UMR 5270, INL, F-69621, Villeurbanne, France.
Basic CMOS and BiCMOS processes have allowed implementation of buried double junction (BDJ) and buried triple p-n junction (BTJ) device structures [3-22]. Using an advanced CMOS technology, we can design and integrate a buried quad junction (BQJ) photodetector for specific applications [23-28].

For system design, we propose in this paper an optoelectrical model of the BQJ photodetector, with the aim of allowing design optimization at device, circuit and system levels, including associated signal processing electronics. The proposed model was built with a physically-based approach, and has been integrated in EDA software for fast and accurate simulation study, based on analytical expressions.

The paper contains 6 sections. Following the introduction, the second section describes the structure of the BQJ photodetector, its operation and discusses the potential applications. The physical modeling of the photocurrent components inside the detector is presented in the third section. Section 4 proposes an equivalent circuit of the device for large-signal analysis. The fifth section is for model validation by comparing characteristics of the $\mathrm{BQJ}$ detector, determined from the model with results from TCAD simulations and experimental measurements. Section 6 concludes this paper.

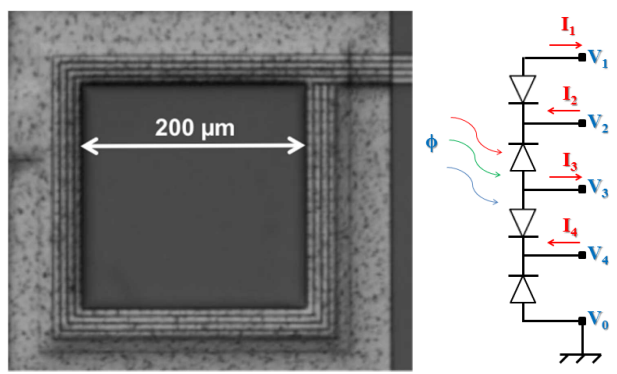

Fig. 1 The BQJ sensor studied.

\section{BURIED QUAD JUNCTION PHOTODETECTOR}

After a detailed presentation of the structure under study, its operation and applications are presented, using a proprietary high voltage CMOS process (HV-CMOS) at Teledyne DALSA Semiconductor Inc. (Bromont, Canada). A picture of the device is shown in Fig. 1.

\section{A. Structure}

The device consists of 4 vertically-stacked buried p-n junction photodiodes. Its implementation is illustrated in Fig. 2 , with formation of its 4 junctions as follows: 


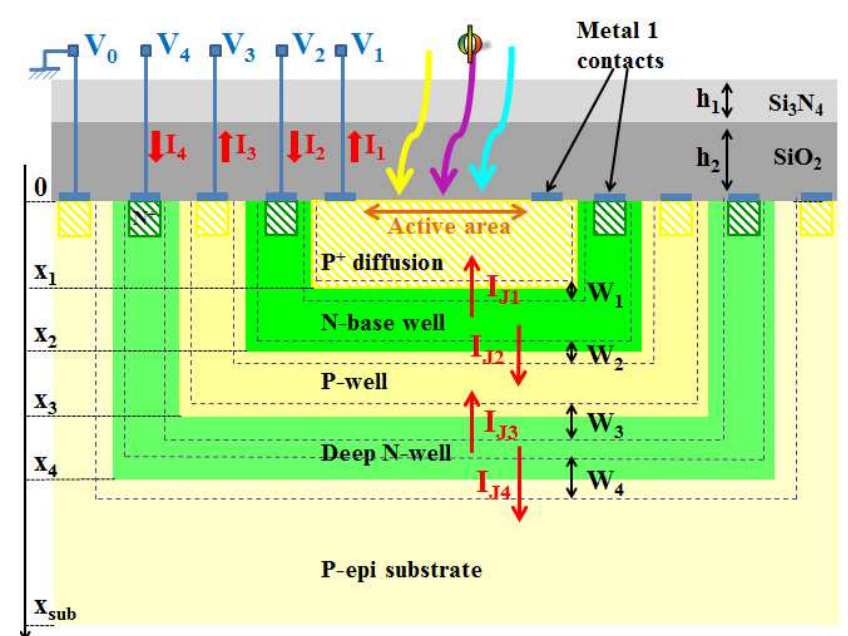

Fig. 2 Simplified cross-section of the BQJ photodetector.

- $\mathrm{J}_{1}$ : shallow $\mathrm{P}^{+}$-diffusion / N-base well junction.

- $\mathrm{J}_{2}$ : N-base well / P-well junction.

- $\mathrm{J}_{3}: \mathrm{P}$-well / deep $\mathrm{N}$-well junction.

- $\mathrm{J}_{4}$ : deep N-well / P-epi substrate junction.

The detector surface is covered with both $\mathrm{Si}_{3} \mathrm{~N}_{4}$ and $\mathrm{SiO}_{2}$ passivation layers. The active photodetection area, $\mathrm{A}_{\mathrm{PH}}$, corresponds to the surface of the $\mathrm{P}^{+}$-diffusion layer, located between the contact electrodes (see Fig. 2). The P-substrate is grounded and the 4 outputs correspond to the $\mathrm{P}^{+}$-diffusion, $\mathrm{N}$ base, P-well and deep N-well contacts, respectively.

\section{B. Operation}

All buried $p$-n junctions $\left(\mathrm{J}_{1}\right.$ to $\left.\mathrm{J}_{4}\right)$ are reverse-biased to operate in photoconductive mode. The bias conditions are: $\mathrm{V}_{\mathrm{J} 1}=\mathrm{V}_{2}-\mathrm{V}_{1}>0 \mathrm{~V}, \mathrm{~V}_{\mathrm{J} 2}=\mathrm{V}_{2}-\mathrm{V}_{3}>0 \mathrm{~V}, \mathrm{~V}_{\mathrm{J} 3}=\mathrm{V}_{4}-\mathrm{V}_{3}>0$ $\mathrm{V}$ and $\mathrm{V}_{\mathrm{J} 4}=\mathrm{V}_{4}-\mathrm{V}_{0}>0 \mathrm{~V}$, where $\mathrm{V}_{1}, \mathrm{~V}_{2}, \mathrm{~V}_{3}, \mathrm{~V}_{4}$ and $\mathrm{V}_{0}$ are the potentials respectively applied to the $\mathrm{P}^{+}$-diffusion, the $\mathrm{N}$ base well, the $\mathrm{P}$-well, the deep $\mathrm{N}$-well and the P-epi substrate. Thus, there are 4 output currents ( $I_{1}$ to $I_{4}$ in Fig. 2):

$$
\begin{aligned}
& \mathrm{I}_{1}=\mathrm{I}_{\mathrm{J} 1} \\
& \mathrm{I}_{2}=\mathrm{I}_{\mathrm{J} 1}+\mathrm{I}_{\mathrm{J} 2} \\
& \mathrm{I}_{3}=\mathrm{I}_{\mathrm{J} 2}+\mathrm{I}_{\mathrm{J} 3} \\
& \mathrm{I}_{4}=\mathrm{I}_{\mathrm{J} 3}+\mathrm{I}_{\mathrm{J} 4}
\end{aligned}
$$

where $\mathrm{I}_{\mathrm{J} \theta}$, with $\theta=1, \ldots, 4$, are the currents flowing through each junction. Under illumination, each junction current is composed of a photo-generated component $\left(\mathrm{I}_{\mathrm{PH} \theta}\right)$ and a dark component $\left(\mathrm{I}_{\mathrm{DC} \theta}\right)$ :

$$
\mathrm{I}_{\mathrm{J} \theta}=\mathrm{I}_{\mathrm{PH} \theta}+\mathrm{I}_{\mathrm{DC} \theta}
$$

The device operation is based on the optical absorption properties of silicon, where the absorption depth depends on the incident light wavelength and each stacked junction has its own distinct spectral sensitivity. Indeed, shorter wavelengths are absorbed near the silicon surface, while longer ones have deeper penetrations. Consequently, the shallow junction $\left(\mathrm{J}_{1}\right)$ is sensitive to short wavelengths, as it collects only photogenerated carriers near the silicon surface. In contrast, the deepest junction $\left(\mathrm{J}_{4}\right)$ is more sensitive to red/NIR light, thanks to its collection of photo-generated carriers in the deeper region. The two other junctions $\left(\mathrm{J}_{2}\right.$ and $\left.\mathrm{J}_{3}\right)$ are more sensitive to the middle of the visible spectrum. The 4 spectral responses resemble to bandpass filters, centered on 4 different wavelengths. Fig. 3 exhibits the normalized photocurrents

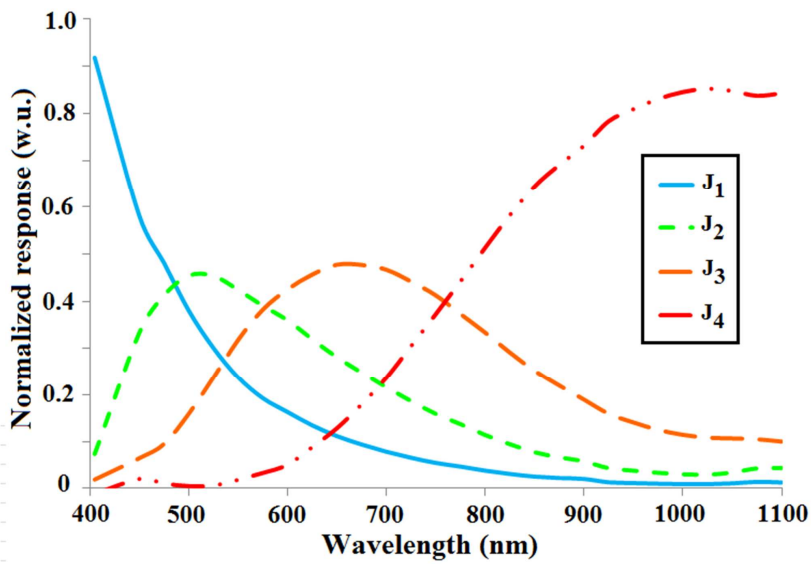

Fig. 3 Relative photocurrents contribution of the BQJ photodetector versus wavelength (measurement result).

contribution of the BQJ photodetector versus wavelength, $\lambda$, defined by:

$$
\mathrm{N}_{\theta}(\lambda)=\frac{\mathrm{I}_{\mathrm{PH} \theta}(\lambda)}{\sum_{\theta=1}^{4} \mathrm{I}_{\mathrm{PH} \theta}(\lambda)}
$$

\section{Applications}

With buried multiple p-n junction (BMJ) photodetectors, it is possible to quantify at the same instant, different spectral components with a single detector. Moreover, increasing the number of vertically-stacked junctions improves the detector's spectral discriminating ability. It is particularly attractive for multispectral applications, such as color detection, light wavelength characterization and simultaneous spectral analysis of several light sources $[3,4,6,7,9,11,12,14,15$ 17]. It has been also shown that this kind of photodetector is well adapted to optical data communication of more than 100 Mbits/s [18-20], where the BMJ photodetectors permit the natural demultiplexing of separate incident light sources.

In biomedical and chemical applications [5, 8, 10, 13, 2130], quantitative spectral analysis is often needed. As illustrated from Fig. 4, knowing the individual spectral response of the junctions, $S_{\theta}$, and the incident light source profile, $G(\lambda)$, we can monitor the optical properties of a medium under test, $H(\lambda)$, with:

$$
\mathrm{I}_{\mathrm{PH} \theta}=\int \mathrm{H}(\lambda) \mathrm{G}(\lambda) \mathrm{S}_{\theta}(\lambda) \mathrm{d} \lambda
$$

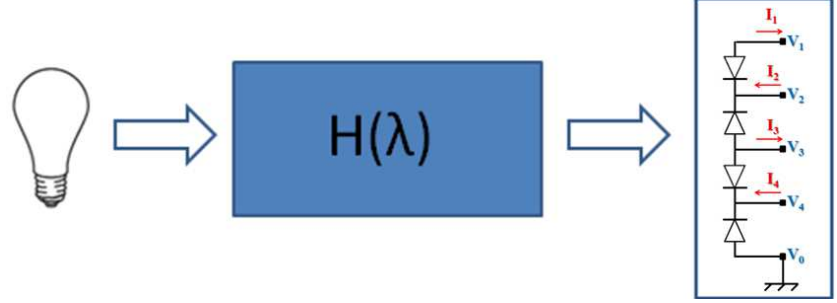

Fig. 4 Illustration of the BMJ photodetector interest in biomedical and chemical fields, such as ELISA test.

In the case of the BQJ photodetector, 4 different components can be analyzed in the same spatiotemporal conditions. Fig. 5 presents the contribution (in percent) of each output to the total photocurrent. These curves are particularly interesting for rapid diagnostics. For example, in NIR spectroscopy [31] or in 3D image reconstruction [32], the instrumentation requires a minimum of 2 different light sources, emitted alternatively. Thanks to this kind of sensor, 


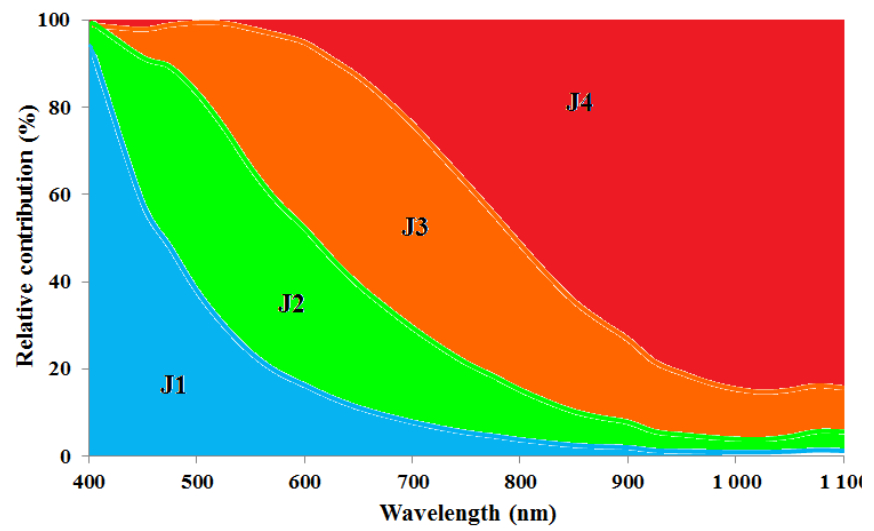

Fig. 5 Relative contribution of each BQJ photocurrent to the total optoelectrical response versus wavelength (measurement result).

light emission (and their detection) can be simultaneous. Thus, the measurement of parameters of interest is correlated (done at the same time and in the same spatial, physiological and electrical conditions).

In addition, noise and parasitic signal rejection coming from light source(s) or transmission channel $(\mathrm{H}(\lambda))$ is improved in comparison to simple photodiodes. Indeed, all spectral responses are taken in the same site and they can be based on the current ratios [12]. For instance, in Fig. 3 and Fig. 5, oscillations due to reflection are suppressed.

Moreover, fewer additional components, such as optical filters or $\operatorname{prism}(\mathrm{s})$ to discriminate the incident light, are required for very specific application, such as fluorescence detection [23]. Thus, additional cost of non-standard production's step is minimized or null.

Finally, for consumer applications such as CMOS APS image sensors, photodetectors require a minimum surface area (less than ten microns, typically) with high fill factors (ideally $100 \%$ ) [33]. However, with this kind of photodetector, by superposition of layers ( $\mathrm{P}$ and $\mathrm{N}$ ) with pads, a significant area of the sensor doesn't participate to the detection. Indeed, the counterpart of this photodetector use is it low fill factor (FF) [34]. In Fig. 6, the FF is given for a square BQJ photodetector according to the dimension of its edges. This type of sensor is generally suitable for applications necessitating a rather large collection surface (a few tens or hundreds of microns aside). However, this must be in contrast to the fact that most conventional image sensors use an array of laterally arranged simple photodiodes, covered with different filters (at least 3), for color selectivity. As each photodetector records only one

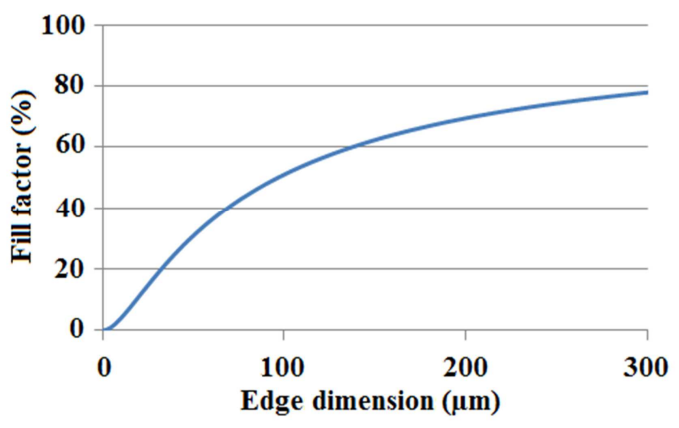

Fig. 6 Fill factor of a square BQJ photodetector versus its size. color, the incident light is rebuilt by combining the output signals of neighboring pixels. Thus, as well as the cost of filters, major drawbacks of these sensors are the increased silicon area, reduction of light gathering and color artifact [17].

\section{MODELING OF THE BQJ PHOTOCURRENTS}

When incident monochromatic light impinges on the active photodetection area of the BQJ photodetector, a part, $\Phi_{t}$, of the initial photon flow, $\Phi$, is transmitted in the device:

$$
\Phi_{\mathrm{t}}(\lambda)=(1-\mathrm{R}(\lambda)) \Phi
$$

where $R(\lambda)$ is the reflection coefficient, precisely defined in $[13,35-37]$, which is dependent on the wavelength, $\lambda$.

Light with energy, $\mathrm{E}(\lambda)$, greater than the silicon bandgap, propagates through the silicon. Though electron-hole pairs were photo-generated along the entire path depth-wise through the material, most of the photo-carriers are generated in a region $\delta \mathrm{x}_{0}$, centered at depth $\mathrm{x}_{0}$, according to the following generation wavelength-dependent rate equation:

$$
\mathrm{G}_{\mathrm{PH}}(\mathrm{x}, \lambda)=\Phi_{\mathrm{t}}(\lambda) \alpha(\lambda) \mathrm{e}^{-\alpha(\lambda) \mathrm{x}}
$$

where $\alpha(\lambda)$ is the absorption coefficient, that depends on the wavelength, but also doping concentrations and temperature [38-39].

The 4 junctions serve to collect photo-generated electronhole pairs, each resulting in a junction photocurrent. Each photocurrent has 3 different components: a drift current $\left(\mathrm{I}_{\mathrm{PHdr} \theta}\right)$ from the collection of photo-generated carriers in the depletion region and 2 diffusion currents $\left(\mathrm{I}_{\mathrm{PHp} \theta}\right.$ and $\left.\mathrm{I}_{\mathrm{PHn} \theta}\right)$ from both adjacent quasi-neutral zones (QNZ) [6, 13, 35] (see Fig. 7):

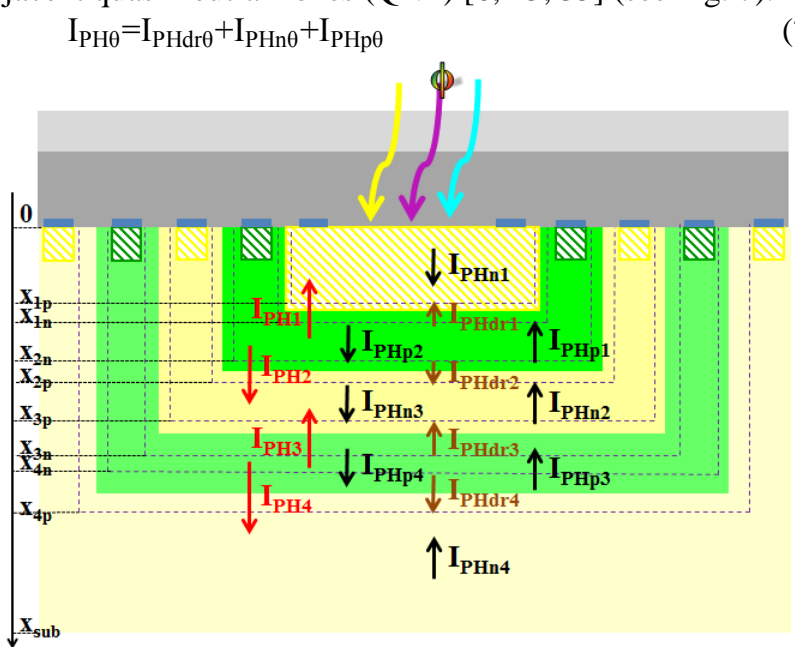

Fig. 7 Photocurrent components in the BQJ structure.

\section{A. Drift Components}

In the depletion region, the internal electric field imposed by the reverse bias separates the photo-generated carriers by preventing their recombination. As the recombination process is negligible, this leads to a drift current which, for monochromatic illumination, can be simply calculated by integrating the generation rate over the depletion layer:

$$
\begin{aligned}
\mathrm{I}_{\mathrm{PHdr} \theta}(\lambda) & =\mathrm{qA}_{\mathrm{PH}} \Phi_{\mathrm{t}}(\lambda) \int_{\mathrm{W}_{\theta}} \mathrm{G}_{\mathrm{PH}}(\mathrm{x}, \lambda) \mathrm{dx} \\
& =\mathrm{A}_{\mathrm{PH}} \mathrm{S}_{\mathrm{PHdr} \theta}(\lambda) \Phi(\lambda)
\end{aligned}
$$


where $\mathrm{W}_{\theta}$ (where $\theta$ from 1 to 4 ) represent the depletion-layer widths (see Fig. 2). They are dependent on the applied voltages and the doping levels. $\mathrm{S}_{\mathrm{PHdr} \theta}$ denote the drift spectral sensitivities.

\section{B. Diffusion Components}

In a QNZ, the newly photo-generated carriers modify the existing electron and hole densities. For the majority carriers in the zone, this variation is negligible compared to the high concentration of dopants. However, for the minority carriers, the contribution of photo-carriers generates a significant concentration gradient. This results in the displacement of charges from their point of generation to the nearest depletion region. Reaching the depletion region, they are driven by the electric field in the region, giving rise to a diffusion component. Therefore, inside the detector structure, the QNZ of the $\mathrm{P}^{+}$-diffusion, $\mathrm{P}$-well and $\mathrm{P}$-epi substrate layers produce 4 photocurrent components due to diffusion of electrons, denoted by $\mathrm{I}_{\mathrm{PHn} 1}, \mathrm{I}_{\mathrm{PHn} 2}, \mathrm{I}_{\mathrm{PHn} 3}$ and $\mathrm{I}_{\mathrm{PHn} 4}$ (see Fig. 7). Similarly, the QNZ of N-base and the deep $\mathrm{N}$-well layers produce 4 photocurrents by diffusion of holes, noted $\mathrm{I}_{\mathrm{PHp} 1}, \mathrm{I}_{\mathrm{PHp} 2}, \mathrm{I}_{\mathrm{PHp} 3}$ and $\mathrm{I}_{\mathrm{PHp} 4}$ (see Fig. 7). It is noted that the N-base well, P-Well and deep $\mathrm{N}$-well layers are common to 2 junctions, the photogenerated minority carriers are directed to the nearest depletion region. This leads to the production of 2 diffusion currents in opposite directions for each QNZ.

The calculation of these diffusion currents requires the solving of the continuity and Fick's equations. Therefore, in steady state, the following expression is valid for each QNZ:

$$
\Delta \mathrm{j}_{\theta}(\lambda)=B_{\theta 1} \mathrm{e}^{-\mathrm{x} / \mathrm{L}_{j \theta}}+\mathrm{B}_{\theta 2} \mathrm{e}^{\mathrm{x} / \mathrm{L}_{\mathrm{j} \theta}}+\frac{\Phi_{\mathrm{t}}(\lambda) \alpha(\lambda) \tau_{\mathrm{j} \theta}}{1-\left(\alpha(\lambda) \mathrm{L}_{\mathrm{j} \theta}\right)^{2}} \mathrm{e}^{-\alpha(\lambda) \mathrm{x}}
$$

where $\Delta \mathrm{j}_{\theta}$ are the variations of minority carrier concentration in each QNZ, with $\mathrm{j}=\mathrm{n}$ for electrons and $\mathrm{p}$ for holes; $\mathrm{L}_{\mathrm{j} \theta}$ are the diffusion lengths of the minority carriers; $\tau_{j \theta}$ are the corresponding time constants; the real numbers, $\mathrm{B}_{1 \theta}$ and $\mathrm{B}_{2 \theta}$, are defined from the following boundary conditions:

$$
\begin{aligned}
& \mathrm{S}_{\mathrm{rP}+} \Delta \mathrm{n}_{1}(0)=\left.\mathrm{D}_{\mathrm{nP}+} \frac{\partial \Delta \mathrm{n}_{1}}{\partial \mathrm{x}}\right|_{\mathrm{x}=0} \\
& \mathrm{~S}_{\mathrm{rPsub}} \Delta \mathrm{n}_{4}\left(\mathrm{x}_{\text {sub }}\right)=\left.\mathrm{D}_{\mathrm{nPsub}} \frac{\partial \Delta \mathrm{n}_{4}}{\partial \mathrm{x}}\right|_{\mathrm{x}=\mathrm{x}_{\text {sub }}} \\
& \Delta \mathrm{n}_{1}\left(\mathrm{x}_{1 \mathrm{p}}\right)=\Delta \mathrm{n}_{2}\left(\mathrm{x}_{2 \mathrm{p}}\right)=\Delta \mathrm{n}_{3}\left(\mathrm{x}_{2 \mathrm{p}}\right)=0 \\
& \Delta \mathrm{n}_{2}\left(\mathrm{x}_{3 \mathrm{p}}\right)=\Delta \mathrm{n}_{3}\left(\mathrm{x}_{3 \mathrm{p}}\right)=\Delta \mathrm{n}_{4}\left(\mathrm{x}_{4 \mathrm{p}}\right)=0 \\
& \Delta \mathrm{p}_{1}\left(\mathrm{x}_{1 \mathrm{n}}\right)=\Delta \mathrm{p}_{2}\left(\mathrm{x}_{1 \mathrm{n}}\right)=\Delta \mathrm{p}_{1}\left(\mathrm{x}_{2 \mathrm{n}}\right)=\Delta \mathrm{p}_{2}\left(\mathrm{x}_{2 \mathrm{n}}\right)=0 \\
& \Delta \mathrm{p}_{3}\left(\mathrm{x}_{3 \mathrm{n}}\right)=\Delta \mathrm{p}_{4}\left(\mathrm{x}_{3 \mathrm{n}}\right)=\Delta \mathrm{p}_{3}\left(\mathrm{x}_{4 \mathrm{n}}\right)=\Delta \mathrm{p}_{4}\left(\mathrm{x}_{4 \mathrm{n}}\right)=0
\end{aligned}
$$

Here, $\mathrm{S}_{\mathrm{rP}+}$ and $\mathrm{S}_{\mathrm{rPsub}}$ are the surface recombination velocities on the device's top and bottom, respectively; $\mathrm{D}_{\mathrm{nP}+}$ and $\mathrm{D}_{\mathrm{nPsub}}$ correspond to the diffusion constant of the $\mathrm{P}^{+}$-diffusion and the P-substrate, respectively.

Finally, the diffusion photocurrents, at points x', are given by:

$$
\mathrm{I}_{\mathrm{PH} \theta}(\lambda)= \pm\left.\mathrm{qA}_{\mathrm{PH}} \mathrm{D}_{\mathrm{j} \theta} \frac{\partial \Delta \mathrm{j}_{\theta}(\lambda)}{\partial \mathrm{x}}\right|_{\mathrm{x}}=\mathrm{A}_{\mathrm{PH}} \mathrm{S}_{\mathrm{PH} \theta}(\lambda) \Phi(\lambda)
$$

where the electrons flow is considered positive, while the holes flow is negative; $x^{\prime}$ corresponds to the boundary depths presented in Fig. 7 (i.e., $0, \mathrm{x}_{\mathrm{j} \theta}$ and $\mathrm{x}_{\mathrm{sub}}$ ); $\mathrm{S}_{\mathrm{PH} \theta}$ denote the diffusion spectral sensitivities.

From equations (8) and (11), (7) can be rewritten as:

$$
\begin{aligned}
\mathrm{I}_{\mathrm{PH} \theta}(\lambda) & =\mathrm{A}_{\mathrm{PH}}\left(\mathrm{S}_{\mathrm{PHdr} \theta}(\lambda)+\mathrm{S}_{\mathrm{PHn} \theta}(\lambda)+\mathrm{S}_{\mathrm{PHp} \theta}(\lambda)\right) \Phi(\lambda) \\
& =\mathrm{A}_{\mathrm{PH}} \mathrm{S}_{\mathrm{PH} \theta}(\lambda) \Phi(\lambda)
\end{aligned}
$$

$$
\mathrm{S}_{\theta}(\lambda)=\frac{\mathrm{I}_{\mathrm{PH} \theta}(\lambda)}{\mathrm{P}_{\mathrm{OPT}}(\lambda)}=\frac{\mathrm{I}_{\mathrm{PH} \theta}(\lambda)}{\mathrm{A}_{\mathrm{PH}} \mathrm{E}(\lambda) \Phi(\lambda)}=\frac{1}{\mathrm{E}(\lambda)} \mathrm{S}_{\mathrm{PH} \theta}(\lambda)
$$

with $\mathrm{E}(\lambda)=\mathrm{hc} / \lambda$, where $\mathrm{h}$ is the Planck's constant, c denotes the speed of light in vacuum, q represents the electron charge and $\mathrm{P}_{\mathrm{OPT}}(\lambda)$ is the optical power.

\section{EQUIVALENT CIRCUIT}

For fast system on chip (SoC) design, simulation tools with reliable models of all components are essential. Based on the previous considerations, associated to earlier works [6, 12-13, 41-46], we propose an equivalent circuit of the BQJ photodetector here for large-signal analysis.

Large-signal operation corresponds to the case where the device operates either in steady-state (i.e., DC) or in a transient state. Small-signal and noise models can be deduced from this equivalent circuit [12-13] for various computational analyses (AC, noise, sensitivities, etc.). Thus, it is possible to perform accurate and rapid simulation at different levels (component, circuit or system).

The proposed equivalent circuit of the photodetector for large-signal operation is shown in Fig. 8, where the block on the right is the physical equivalent circuit of the BQJ photodetector. In contrast, the block on the left hasn't physical reality. It is an equivalent modeling to take into account the intrinsic opto-electrical response speed of the device. Thus, we have:

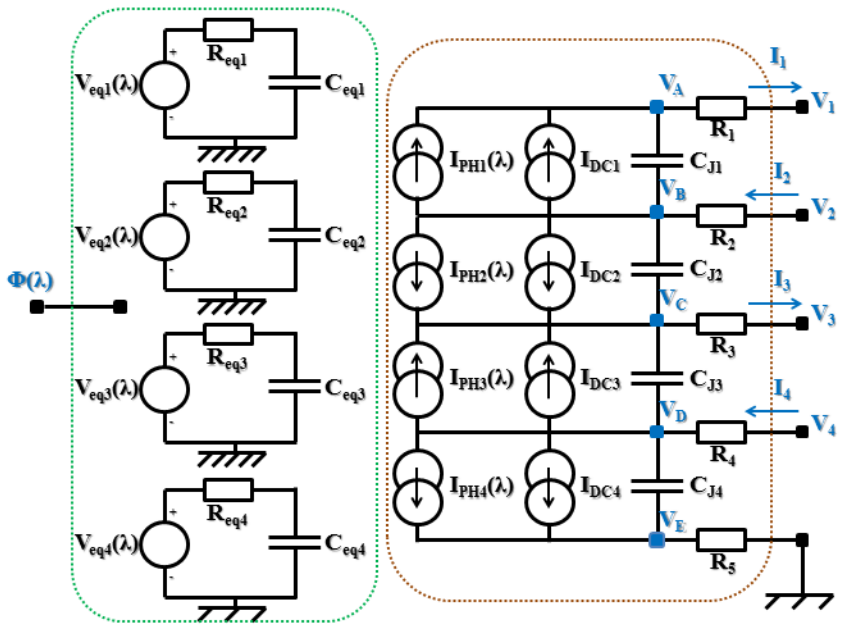

Fig. 8 Large-signal equivalent circuit of the BQJ photodetector.

- The $\mathrm{V}_{\text {eq } \theta}$ are the equivalent voltage sources controlled by $\Phi(\lambda)$ (i.e., image of the incident radiation), where $\mathrm{V}_{\mathrm{eq \theta} \theta}(\lambda)=\mathrm{K}_{\phi \theta} \Phi(\lambda)$, with $\mathrm{K}_{\phi \theta}=1 \mathrm{~V} . \mathrm{cm}^{2}$.s/photon.

- The $\mathrm{R}_{\mathrm{eq} \theta} \mathrm{C}_{\mathrm{eq} \theta}$ are the opto-electrical time constants of the equivalent networks representing the photodetector. They model the response's time to generate photocurrents when an incident light suddenly reaches the surface of the photodetector. They are approximated by a first order model and defined by the cut-off frequencies [18-20, 4147]:

$$
\mathrm{f}_{\mathrm{c} \theta-3 \mathrm{~dB}}=\frac{1}{2 \pi \mathrm{R}_{\mathrm{eq} \theta} \mathrm{C}_{\mathrm{eq} \theta}}=\frac{2.4}{2 \pi \tau_{\theta}}
$$

with:

$$
\tau_{\theta} \approx 2.2 \sqrt{\left(\tau_{\mathrm{n} \theta}{ }^{2}+\tau_{\mathrm{dr} \theta}{ }^{2}+\tau_{\mathrm{p} \theta}^{2}\right)}
$$

and the total spectral responses become: 
where the $\tau_{\mathrm{n} \theta}$ are the diffusion times of the photogenerated electrons in the P-type QNZ; the $\tau_{\mathrm{p} \theta}$ are the diffusion times of the photo-generated holes in the $\mathrm{N}$ type QNZ (the both previously defined by $\tau_{\mathrm{j} \theta}$ ); the $\tau_{\mathrm{dr} \theta}$ are the photo-carrier transit times in the depletion layers. The drift component has a faster response than the diffusion one, as the charge collecting process differ. Yet, in function of the nature of the incident light, photo-carriers are generated mostly in a specific zone, which imposes the most part of this time $\tau_{\theta}$. In the worst case, they conduct to both rise and fall times of some nanoseconds. Note that there are also the usual purely electrical time constants, associated with impedance connected to the BQJ outputs and the junction capacitances, $\mathrm{C}_{\mathrm{J} \theta}$ (block on the right in Fig. 8).

- $\mathrm{I}_{\mathrm{PH} \theta}$ are the photocurrent sources. In Fig. 8, they are current sources controlled by the voltage across $\mathrm{C}_{\mathrm{eq} \theta}$. Thus, we have in the frequency domain:

$$
\mathrm{I}_{\mathrm{PH} \theta}(\lambda, \mathrm{f})=\frac{\mathrm{K}_{\mathrm{V} \theta}}{1+\mathrm{j}_{\frac{\mathrm{f}}{\mathrm{c} \theta-3 \mathrm{~dB}}}} A_{\mathrm{PH}} \mathrm{S}_{\mathrm{PH} \theta}(\lambda) \mathrm{V}_{\mathrm{eq} \theta}(\lambda)
$$

where $\mathrm{K}_{\mathrm{V} \theta}=1 \mathrm{~A} / \mathrm{V}$ and $\mathrm{S}_{\mathrm{PH} \theta}$ is defined in (12).

- $\mathrm{R}_{\kappa}$, with $\kappa=1, \ldots, 5$, are the parasitic series resistances of the ohmic contacts and the bulk resistances of the QNZ. They are non-linear elements that depend on the applied bias and reduce the device efficiency. Their values (typically, some ohms) depend mainly on the device layout via both the junctions' area and the number of contacts on each layer. $R_{\kappa}$ can be estimated before the device realization, either manually or from parasitic extraction with EDA software, based on the technology design kit [48].

- $\mathrm{C}_{\mathrm{j} \theta}$ are the junction capacitances. As the transit capacitances are negligible in reverse-bias polarization, only these capacitances $\mathrm{C}_{\mathrm{j} \theta}$ are taken into account. They are well defined from the following equation:

$$
\mathrm{C}_{\mathrm{J} \theta}=\frac{\mathrm{C}_{\mathrm{J} 0 \theta}}{\left(1+\frac{\mathrm{V}_{\mathrm{J} \theta}}{\mathrm{V}_{\mathrm{bi} \theta}}\right)^{\mathrm{M}_{\theta}}}
$$

Here, $\mathrm{C}_{\mathrm{J} 0 \mathrm{\theta}}$ are the effective zero-bias junction capacitances, taking into account both surface and peripheral contributions; $\mathrm{V}_{\mathrm{J} \theta}$ are the reverse voltage biases applied to junctions; $\mathrm{V}_{\mathrm{bi \theta}}$ correspond to the built-in potentials; $\mathrm{M}_{\theta}$ are dimensionless technological parameters that depend on the doping profiles of the junction.

Note that, assimilating these physical capacitances to parallel-plate capacitors, it is possible to have a fairly reliable estimate of the associated depletion layer width $\left(\mathrm{W}_{\theta}\right)$ and its maximum electrical field, from Gauss' law (both parameters being necessary for the calculation of the BQJ currents, both in dark conditions and under illumination).

- $\mathrm{I}_{\mathrm{DC} \theta}$ are the dark current sources, the ubiquitous parasitic leakage current flowing through a p-n junction. They impose a physical limit on the minimum detectable signal [12]. In the voltage range of interest, the involved physical mechanisms are:

- Shockley-Read-Hall (SRH) generation-recombination (GR) process: present in each space-charge region, this mechanism produces a thermal generation current under reverse-bias polarization. At room temperature, it is generally the dominant contribution for moderately doped junctions with low and moderate reverse bias voltage. In the device structure under study, these dark current components, $\mathrm{I}_{\mathrm{DC} \_\mathrm{SRH} \theta}$, are measurable in all junctions (mainly for $\mathbf{J}_{2}$ to $\mathrm{J}_{4}$ ). Their contribution is given by:

$$
\mathrm{I}_{\mathrm{DC} \_\mathrm{SRH} \theta} \approx \mathrm{qA}_{\mathrm{J} \theta} \frac{\mathrm{w}_{\theta}}{2 \tau_{\mathrm{g} \theta}}
$$

where $\mathrm{A}_{\mathrm{J} \theta}$ represents the effective junction areas; the $\tau_{\mathrm{g} \theta}$ denote the effective GR lifetimes [49]. This kind of current is directly proportional to $\mathrm{V}_{\mathrm{J} \theta}$ at the power $\mathrm{M}_{\theta}$ (i.e., $\mathrm{V}_{\mathrm{J} \theta}{ }^{\mathrm{M} \theta}$ ).

- Diffusion mechanism: for a low-doped p-n junction, with a small reverse voltage bias and a junction temperature slightly higher than room temperature, the thermally generated minority carriers move by diffusion from both neutral regions of a junction to its depletion layer, where they recombine. They produce a diffusion current $\left(\mathrm{I}_{\mathrm{d} \theta}\right)$, explained by Shockley [35]. However, as the device is a $\mathrm{P}^{+} \mathrm{NPNP}$ structure, a mutual coupling between neighboring junctions exists and an interdependency of diffusion currents flowing through the junctions is expected in particular bias conditions (similarly to the Ebers-Moll model of bipolar transistors). The analytical expression is obtained through equations (9) and (11), with $\Phi=0$ photon. $\mathrm{cm}^{-2} \cdot \mathrm{s}^{-1}$, equations $(10-\mathrm{a})$ and $(10-\mathrm{b})$ and the following new boundary conditions:

$$
\begin{aligned}
& \Delta \mathrm{n}_{1}\left(\mathrm{x}_{1 \mathrm{p}}\right)=\mathrm{n}_{0 \mathrm{P}+}\left(\exp \left(-\frac{\mathrm{q}}{\mathrm{KT}} \mathrm{V}_{\mathrm{J} 1}\right)-1\right) \\
& \Delta \mathrm{n}_{2}\left(\mathrm{x}_{2 \mathrm{p}}\right)=\Delta \mathrm{n}_{3}\left(\mathrm{x}_{2 \mathrm{p}}\right)=\mathrm{n}_{0 \text { Pwell }}\left(\exp \left(-\frac{\mathrm{q}}{\mathrm{KT}} \mathrm{V}_{\mathrm{J} 2}\right)-1\right) \\
& \Delta \mathrm{n}_{2}\left(\mathrm{x}_{3 \mathrm{p}}\right)=\Delta \mathrm{n}_{3}\left(\mathrm{x}_{3 \mathrm{p}}\right)=\mathrm{n}_{0 \text { Pwell }}\left(\exp \left(-\frac{\mathrm{q}}{\mathrm{KT}} \mathrm{V}_{\mathrm{J} 3}\right)-1\right) \\
& \Delta \mathrm{n}_{4}\left(\mathrm{x}_{4 \mathrm{p}}\right)=\mathrm{n}_{0 \text { Psub }}\left(\exp \left(-\frac{\mathrm{q}}{\mathrm{KT}} \mathrm{V}_{\mathrm{J} 4}\right)-1\right) \\
& \Delta \mathrm{p}_{1}\left(\mathrm{x}_{1 \mathrm{n}}\right)=\Delta \mathrm{p}_{2}\left(\mathrm{x}_{1 \mathrm{n}}\right)=\mathrm{p}_{\text {ONbase }}\left(\exp \left(-\frac{\mathrm{q}}{\mathrm{KT}} \mathrm{V}_{\mathrm{J} 1}\right)-1\right) \\
& \Delta \mathrm{p}_{2}\left(\mathrm{x}_{2 \mathrm{n}}\right)=\Delta \mathrm{p}_{3}\left(\mathrm{x}_{2 \mathrm{n}}\right)=\mathrm{p}_{\text {ONbase }}\left(\exp \left(-\frac{\mathrm{q}}{\mathrm{KT}} \mathrm{V}_{\mathrm{J} 2}\right)-1\right) \\
& \Delta \mathrm{p}_{3}\left(\mathrm{x}_{3 \mathrm{n}}\right)=\Delta \mathrm{p}_{4}\left(\mathrm{x}_{3 \mathrm{n}}\right)=\mathrm{p}_{0 \text { Nwell }}\left(\exp \left(-\frac{\mathrm{q}}{\mathrm{KT}} \mathrm{V}_{\mathrm{J} 3}\right)-1\right) \\
& \Delta \mathrm{p}_{3}\left(\mathrm{x}_{4 \mathrm{n}}\right)=\Delta \mathrm{p}_{4}\left(\mathrm{x}_{4 \mathrm{n}}\right)=\mathrm{p}_{0 \text { Nwell }}\left(\exp \left(-\frac{\mathrm{q}}{\mathrm{KT}} \mathrm{V}_{\mathrm{J} 4}\right)-1\right)
\end{aligned}
$$

where $\mathrm{n}_{0 \mathrm{P}+}, \mathrm{n}_{0 \mathrm{Pwell}}, \mathrm{n}_{\mathrm{OPsub}}, \mathrm{p}_{0 \mathrm{Nb}}, \mathrm{p}_{0 \mathrm{Nwell}}$ are the minority carrier concentrations in each QNZ of the structure at equilibrium; $\mathrm{K}$ is Boltzmann's constant; $\mathrm{T}$ is the absolute temperature.

For a reverse bias higher than $\sim 100 \mathrm{mV}$, this component is independent of $\mathrm{V}_{\mathrm{J} \theta}$.

- Tunneling effect: it is a quantum effect observed in highly doped junctions, even with moderate reverse bias voltage. In such conditions, the band-to-band tunneling (BBT) is not negligible. Its contribution is formulated from the conventional Zener tunneling equation:

$$
\mathrm{I}_{\mathrm{DC} \_t} \approx \sim \mathrm{qV}_{\mathrm{J} \theta} \mathrm{C}_{\mathrm{bbt} \theta} \mathrm{E}_{\mathrm{MAX} \theta}^{3 / 2} \mathrm{e}^{-\mathrm{E}_{0} / \mathrm{E}_{\mathrm{MAX} \theta}}
$$

where $\mathrm{C}_{\mathrm{bbt} \theta}$ and $\mathrm{E}_{0}$ are constants that are highly dependent on the device material; the $\mathrm{E}_{\mathrm{MAX} \theta}$ are the maximum electrical fields in each depletion zone. 
Typically, for $\mathrm{V}_{\mathrm{J} \theta}$ higher than a few volts, this current varies mainly as $\exp \left(\mathrm{V}_{\mathrm{J} \theta}{ }^{\gamma}\right)$, where $\gamma$ is a real number.

More complete information about dark currents can be found in [12-13, 35, 49-51].

\section{MODEL VALIDATION}

We have performed model validation by comparing the device's characteristics computed from our developed model with the ones by both TCAD simulations and measurements. Dark current has been also analyzed in order to identify the dominant physical mechanism.

We have measured various BQJ detectors, fabricated with the Teledyne DALSA Semiconductor High-Voltage $0.8 \mu \mathrm{m}$ CMOS technology (shown in Fig. 1). All measurements were

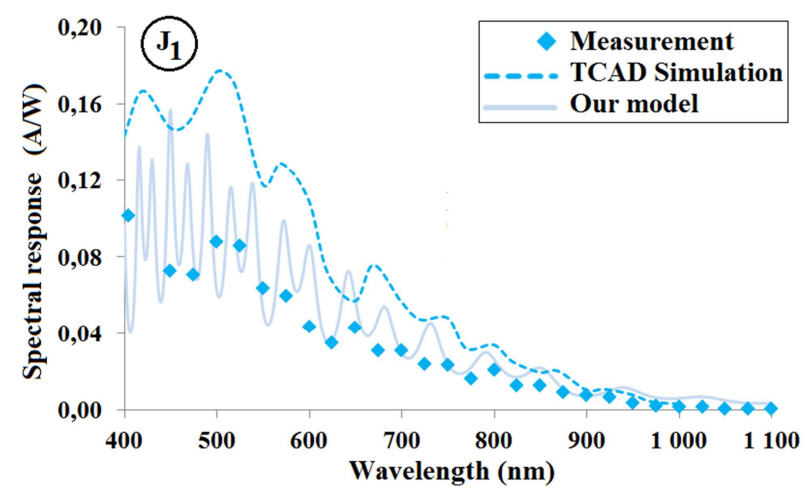

a)

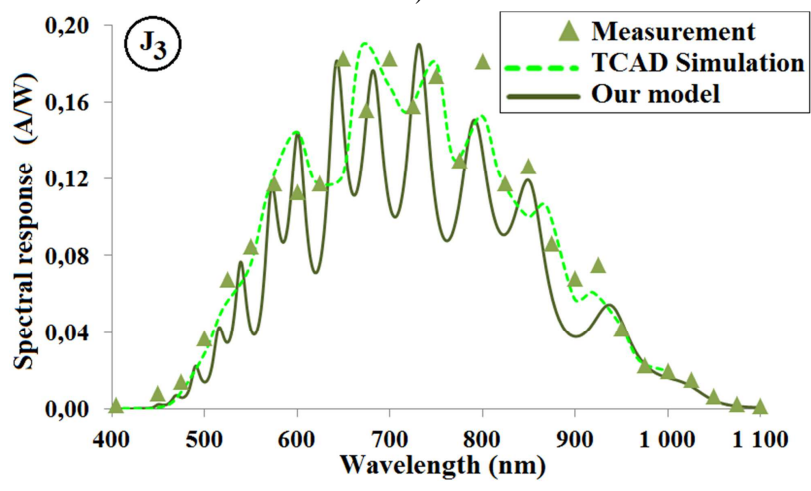

c) performed by direct probing of the detectors on the wafer. For all devices, the active area $\left(\mathrm{A}_{\mathrm{PH}}\right)$ is $200 \mu \mathrm{m} \times 200 \mu \mathrm{m}$, with a $\mathrm{P}^{+}$-diffusion area of $206.2 \times 206.2 \mu \mathrm{m}^{2}, 220.4 \times 220.4 \mu \mathrm{m}^{2}$ for the N-base layer, $233.6 \times 233.6 \mu \mathrm{m}^{2}$ for the P-well layer and $249.8 \times 249.8 \mu \mathrm{m}^{2}$ for the deep N-well layer (i.e., $\mathrm{A}_{\mathrm{J} \theta}$ ). According to Fig. 2, the depth of the junctions are $x_{1}=0.3 \mu \mathrm{m}$, $\mathrm{x}_{2}=1.35 \mu \mathrm{m}, \mathrm{x}_{3}=3.5 \mu \mathrm{m}$ and $\mathrm{x}_{4}=11 \mu \mathrm{m}$.

The experimental BQJ spectral responsivity characteristics are obtained by illuminating the device with a focused spot (diameter of $100 \mu \mathrm{m}$ ) with a broad-spectrum source, and with $20 \mathrm{~nm}$ band-pass optical filters (FWHM). Due to material at our disposal, they are realized over the 400-1100 nm range, with a wavelength step of $25 \mathrm{~nm}$ (except between the two first points, at 405 and $450 \mathrm{~nm}$ ). Thus, note that, due to these optical filters, each measurement point is an average on the

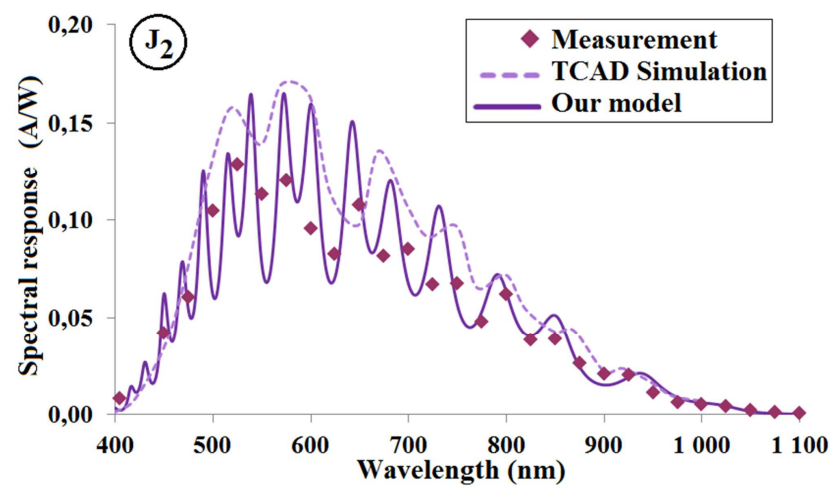

b)

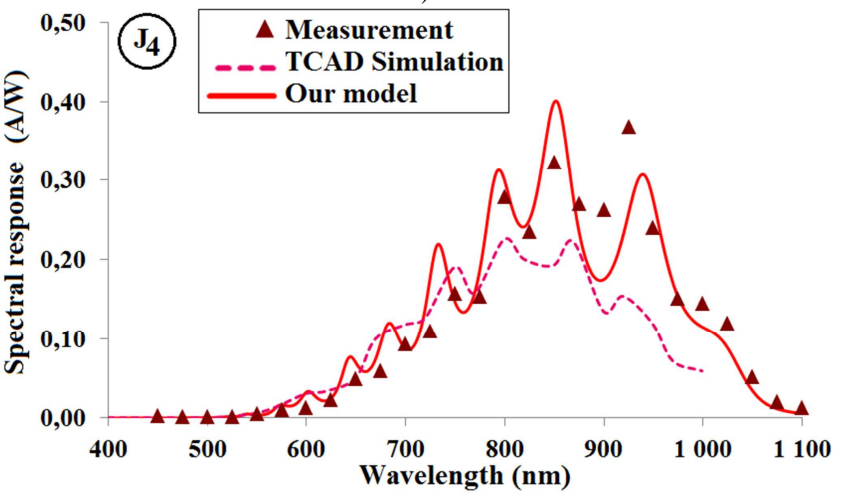

d)

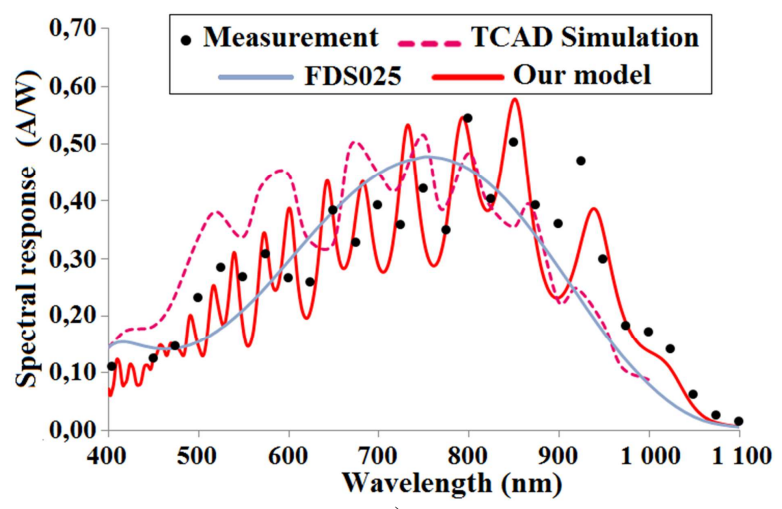

e)

Fig. 9 Comparison of simulated spectral responses from the BQJ model with measured data and TCAD simulation (Fig. 9a to 9d correspond to the spectral response of the 4 junctions and Fig. $9 \mathrm{e}$ is the total spectral response). 
bandwidth of the used filter. The optical power at the output of the filter in each distinct spectral band is determined with a calibrated power-meter (Model 1830-C + 818UV Si detector, Newport Corp.). Current measurements in reverse bias conditions are carried out simultaneously on all BQJ's outputs with a source meter unit (SMU) mainframe (HP4142B, Keysight Tech.), where each measurement point is the average of several acquisitions. Then, the photocurrents are deduced from (1), after subtraction of the dark currents components.

Simulations have also been performed using the Taurus Medici semiconductor modeling package (Synopsys Inc.). To reduce the computation time, the detector structure is modeled with idealized cylindrical symmetry. The spectral characteristics of the detector are computed for incident light ranging from $400 \mathrm{~nm}$ to $1000 \mathrm{~nm}$, with a variable wavelength step between 20 and $30 \mathrm{~nm}$, close to the employed step during measurement and, also, in order to obtain the best tradeoff between precision and computational load.

Moreover, we have implemented our model firstly using MATLAB (Mathwork Inc.) for fast analysis of our development. Photocurrents, $\mathrm{I}_{\mathrm{PH} \theta}$, are calculated according to their analytical expressions, especially. All the key parameters, such as $\alpha(\lambda)$, are also modeled, and the dimensions of all regions are determined. The $\mathrm{I}_{\mathrm{PH} \theta}$ calculations involve determination of various parameters including physical constants, process parameters of the employed technology, temperature and bias voltages.

In a second time, these same equations, in association to the proposed equivalent circuit, have been introduced in Questa ADMS (Mentor Graphics Inc.) with the VHDL-AMS language, as in [52]. Thus, for future perspectives, the implemented model can be easily employed in a circuit and system simulation environment, where other component's models, coming from various libraries (SPICE, VHDL-AMS, etc.) can be plugged on it, for instance. This is particularly attractive for rapid design of SoC, where the BQJ photodetector is used. Note that TCAD tools are rather used for simulating semiconductor performance, based on a drawing structure. It is now possible to couple them with SPICE-like simulator. However, the computation time is quite long and its realization can be complex, with usual convergence problems.

Fig. 9 represents the spectral responses of the BQJ detector obtained from the 3 approaches in the following conditions: at room temperature and for $\mathrm{V}_{\mathrm{J} \theta}=1.5 \mathrm{~V}$. Fig. 9a to $9 \mathrm{~d}$ correspond to each of the 4 junctions respectively, and Fig. 9e represents the sum of the 4 spectral responses, with a spectral response of a commercialized photodiode (FDS025, Thorlabs Inc.), added for comparison. The oscillations affecting the spectral characteristics of the $\mathrm{BQJ}$ detector are due to self-interferences of reflections from different dielectric layers on top of the detector surface $\left(\mathrm{air} / \mathrm{Si}_{3} \mathrm{~N}_{4} / \mathrm{SiO}_{2} / \mathrm{Si}\right)$. They are more pronounced in the proposed model, compared to the TCAD simulations and measurements, because narrower wavelength bands were used. Indeed, with our model's results in Fig. 9, a wavelength step of $1 \mathrm{~nm}$ has been chosen because, as our simulation time is short (some seconds, compared to many minutes with Taurus Medici), this low step permits to perfectly reproduce the oscillation effect due to reflection. In contrast to measurement and TCAD simulation, where we have a subsampling effect, the constraint imposed by the Nyquist-Shannon theorem is respected here and we avoided the averaging effect. Consequently, our results show larger amplitude variation and the oscillation effect is more visible than with measurement and TCAD data. However, note that this step is easily modifiable in our program. All spectral responses exhibit good agreement between the proposed model and TCAD simulations and measurements. The mean relative error on the spectral responses from our model, compared to measurements, is between $6 \%$ and $17 \%$, depending on the considered junction. Factors, such as uncertainties on some basic parameters (such as doping concentrations, depth of junctions, recombination effect at the $\mathrm{SiO}_{2} / \mathrm{Si}$ interface, etc.) and precision of the absorption model [38] (around $10 \%$ ), may explain the observed differences. Changes between our model and TCAD results can be attributed to the following aspects: in addition to the different wavelength step, which conducts to an oscillation effect that seems different and the amplitude's differences, the absorption coefficient model differs. With Taurus Medici, we have employed a basic model [53-55]. In our case, a custom and tested model, described in [13], is used. Moreover, the numerical method, associated the TCAD meshing, could accentuated these differences.

In the case of the normalized responses of Fig. 3, as $R(\lambda)$ is the same for all junctions, introducing (12) in (3), we have:

$$
\mathrm{N}_{\theta}(\lambda)=\frac{\mathrm{S}_{\theta}(\lambda)}{\sum_{\theta=1}^{4} \mathrm{~S}_{\theta}(\lambda)}
$$

Therefore, oscillations due to reflection are suppressed and the mean relative error between measurement and model on these normalized responses is then improved (between $3 \%$ and $12 \%$, rather than $6 \%$ and $17 \%$, previously).

Finally, note that changing the bias conditions from 0 to $5 \mathrm{~V}$ does not significantly affect the spectral responses (less than $5 \%$ ). Thus, the choice of these biases is mainly imposed by considering dark current contributions and optimization of response times, through $\mathrm{W}_{\theta}$. Therefore, to tune the spectral responses for a particular application, adjustment of doping and depth of each junction are the best approach. For a defined fabrication process, adding a metal grid structure at the surface of the photodetector to shift the region of high sensitivity of the photodetector is also an interesting possibility [14].

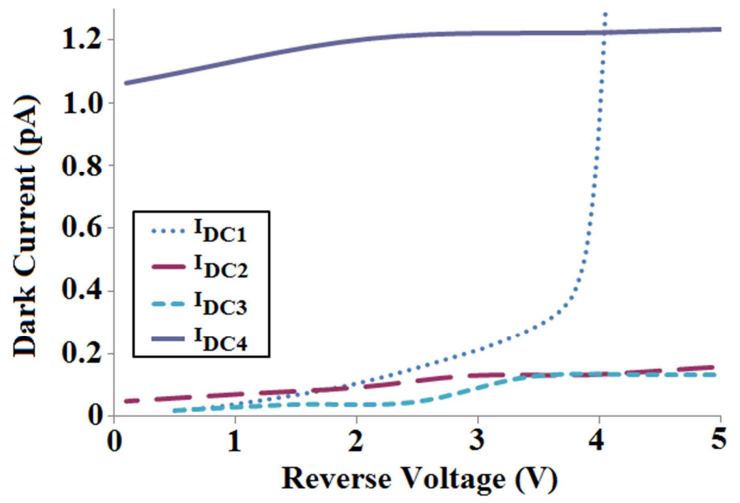

Fig. 10 Dark current characteristic of the 4 junctions.

Dark current characteristics at room temperature have also been measured. They are presented in Fig. 10, where we can define 3 bias ranges on these I/V characteristics, according to 
the main physical mechanisms:

- $0<\mathrm{V}_{\mathrm{J} \theta}<0.5 \mathrm{~V}$ : both SRH generation and diffusion mechanisms contribute to the dark current.

- $\mathrm{V}_{\mathrm{J} \theta}>0.5 \mathrm{~V}: \mathrm{I}_{\mathrm{DC} \theta}$ is proportional to $\left(\mathrm{V}_{\mathrm{J} \theta}\right)^{\mathrm{M}_{\mathrm{J} \theta}}$. Consequently, the SRH generation is predominant.

- $\mathrm{V}_{\mathrm{J} 1}>3.5 \mathrm{~V}$ : the dark current is proportional to the exponential of the junction voltage $\left(\exp \left(\mathrm{V}_{\mathrm{J} 1}^{\gamma}\right)\right)$ in the highly doped junction $J_{1}$. Thus, the BBT effect is predominant in this range.

Also, note that $\mathrm{J}_{4}$ shows the largest dark current contribution for reverse biasing voltages up to $3.5 \mathrm{~V}$. This is because $\mathrm{J}_{4}$ is the lowest doped junction and its depleted zone is the widest. Moreover, it has also the largest surface area in the sidewall region, with more significant surface thermal generation.

Junction capacitances of the device have also been measured independently (the studied junction is reversed bias, while the others are left floating), with HP4280A. Results are presented on Fig. 11. For a $3 \mathrm{~V}$ reverse bias, the model of (17) is in agreement with the measurements on $\mathrm{J}_{2}$ and $\mathrm{J}_{4}$, with less than $5 \%$ deviation. For $J_{3}$, the junction capacitance is overestimated by about $17 \%$. Finally, for a reverse bias greater than $1 \mathrm{~V}$, the surface junction capacitance decreases greatly, which may be explained by a breakdown of $\mathrm{J}_{1}$ in these bias conditions. Indeed, in the study of dark currents, Fig. 10 illustrated the sudden increase of the current with a predominant contribution of tunneling effect.

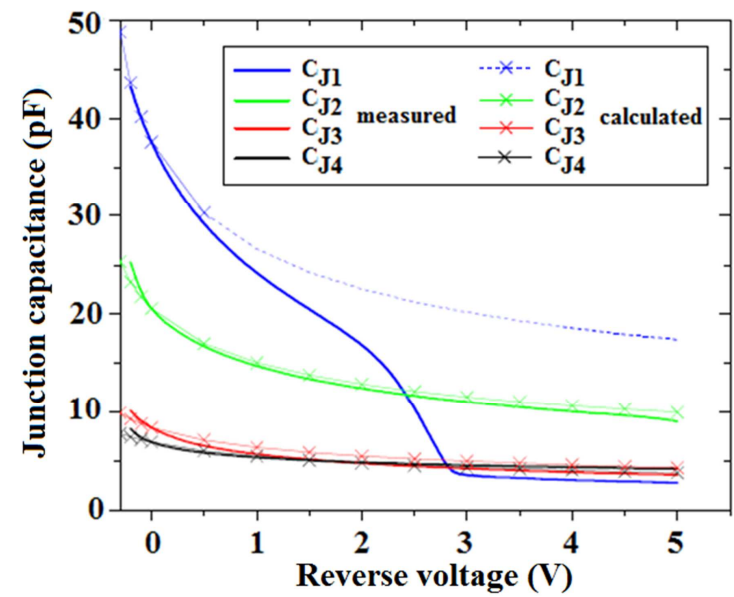

Fig. 11 Evolution of junction capacitance with reverse bias.

\section{CONCLUSION}

A buried quad p-n junction photodetector has been designed and integrated in CMOS technology. This photodetector achieves many improvements over conventional photodiodes, such as analysis of different spectral components in the same spatiotemporal conditions, with a higher common mode rejection. However, it could not be implemented for high resolution imagers, since the fill factor would decrease dramatically with the pixel size. Nevertheless, it could bring special features, such as high sensitivity and high spectral selectivity for scientific and biomedical applications.

For the fast optimized development of its associated analog front-end and signal processing, a physically-based BQJ photodetector model has been developed. It has been integrated in EDA software for component, circuit, system level simulations. A good agreement of the proposed model is obtained with TCAD simulations and measurements for both electrical (dark currents and junction capacitances) and optoelectrical (spectral responses) features.

The perspectives of this work are a statistical study of the main parameters of this model. The design of SoC (ASIC), based on this BQJ photodetector, is also in process. The frontend is then designed and optimized thanks to this model, associated to SPICE-like simulation.

\section{ACKNOWLEDGMENT}

The authors wish to thank Teledyne DALSA Semiconductor Inc. for help in the manufacture of the BQJ photodetector and for the extraction of technological parameters.

This work was performed within the Labex SMART supported by French state funds managed by the ANR within the Investissements d'Avenir program under reference ANR11-IDEX-0004-02.

\section{REFERENCES}

[1] M. Lebby, "Optoelectronics: Successfully penetrating many new markets”, Optoelectronics Industry Development Association, 2006.

[2] H. Zimmermann, "Silicon Optoelectronic Integrated Circuits", SpringerVerlag Berlin and Heidelberg GmbH \& Co. K, Berlin, 2010.

[3] G.N. Lu, M. Ben Chouikha, G. Sou, G., M. Sedjill, "Colour detection using a buried double $\mathrm{p}-\mathrm{n}$ junction structure implemented in the CMOS process", IET, Electronics Letters, vol. 32, no. 6, pp. 120-122, March 1996.

[4] M. Ben Chouikha, G.N. Lu, M. Sedjill, G. Sou, "Colour detection using buried triple pn junction structure implemented in BiCMOS process", IET, Electronics Letters, vol. 34, no. 1, pp. 120-122, January 1998.

[5] G.N. Lu, "A dual-wavelength method using the BDJ detector and its application to iron concentration measurement", OIP, Measurement Science and Technology, vol. 10, no. 4, pp. 312-315, January 1999.

[6] A. Alexandre, G. Sou, M. Ben Chouikha, M. Sedjil, G.N. Lu, G. Alquie, "Modeling and Design of Multi Buried Junctions Detectors for Color Systems Development”, Proc. SPIE, San Diego, CA, USA, vol. 4019, pp. 288-298, July 2000.

[7] R.F. Lyon, P.M. Hubel, "Eyeing the camera: into the next century", Proc. of IS\&T/SID 10th Color Imaging Conference, Scottsdale, Arizona, USA, pp. 349-355, November 2002.

[8] P. Pittet, J.M. Galvan, G.N. Lu, L.J. Blum, D. Leca-Bouvier, "CMOS LIF detection system for capillary analysis", Elsevier, Sensors and Actuators B (Chemical), vol. B97, no. 2, pp. 355-361, February 2004.

[9] D.L. Gilblom, S.K. Yoo, P. Ventura, "Real-time color imaging with a CMOS sensor having stacked photodiodes", Proc. of SPIE, vol. 5210, pp. 105-115, February 2004.

[10] P. Pittet, G.N. Lu, N. Bertoncini, L. Renaud, "CMOS absorbance detection system for capillary electrophoresis", Elsevier, Materials Science and Engineering: C, vol. 26, issue 2-3, pp. 282-289, March 2006.

[11] T. Ross, R.K. Henderson, B. Rae, D. Renshaw, "A buried triple-junction self-reset pixel in a $0.35 \mu \mathrm{m}$ high voltage CMOS process", Proc. of International Image Sensor Workshop, Cliffhouse Resort Ogunquit, Maine, USA, pp. 279-282, June 2007.

[12] S. Feruglio, V. Fouad Hanna, G. Alquie, G. Vasilescu, "Dark Current and Signal-to-Noise Ratio in BDJ Image Sensors", IEEE, Transaction on Instrumentation and Measurement, vol. 55, no. 6, pp. 1892-1903, December 2006.

[13] S. Feruglio, G.N. Lu, P. Garda, G. Vasilescu, "A Review of CMOS Buried Double Junction (BDJ) Photodetector and its Applications", MDPI, Sensors, vol. 8, pp. 6566-6594, October 2008.

[14] Yang, F. Titus, A.H., "Integrated Colour Detectors in 0.18- $\mu \mathrm{m}$ CMOS Technology", IET, Electronics Letters, vol. 43, issue 23, pp. 1279-1281, November 2007.

[15] K. Liang, W. Li, H.R. Ren, X.L. Liu, W.J. Wang, R. Yang, D.J. Han, "Color measurement for RGB white LEDs in solid-state lighting using a 
BDJ photodetector", Elsevier, Displays, vol. 30, no. 3, pp. 107-113, July 2009.

[16] S. Schidl, A. Polzer, H. Zimmermann, "LED wavelength determination sensor system with BiCMOS triple junction photodetector", IET, Electronics Letters, vol. 48, no. 23, pp. 1490-1492, November 2012.

[17] http://www.foveon.com/

[18] A. Polzer, K. Schneider-Hornstein, J. Dong, P. Kostov, H. Zimmermann, "Investigation of triple-junction photodetector in $90 \mathrm{~nm} \mathrm{CMOS}$ technology", Elsevier, Procedia Engineering, vol. 25, pp. 864-867, December 2011.

[19] S. Schidl, A. Polzer, J. Dong, K. Schneider-Hornstein, H. Zimmermann, "Investigation of transient photocurrent response of triple pn junction structure", IET, Electronics Letters, vol. 49, no. 4, pp. 284-285, February 2013

[20] S. Schidl, H. Zimmermann, "AC response of $0.35 \mu \mathrm{m}$ CMOS triple junction photodetector", IET, Electronics Letters, vol. 50, no. 23, pp. 1728-1729, November 2014

[21] S. Schidl, E. Kaniusas, H. Zimmermann, "CMOS chip with multi junction photo detector for sensing biomedical signals", IEEE Sensors conference, Baltimore, MD, pp. 1-4, November 2013.

[22] Z. Zhan, B. Zhou, Z.H. Fu, F.V. Bright, A.N. Cartwright, A.H. Titus, "Filterless optical oxygen sensor based on a CMOS buried double junction photodiode", Elsevier, Sensors and Actuators B : Chemical, vol. 176, pp. 729-735, January 2013.

[23] C. Richard, P. Pittet, S. Martel, L. Ouellet, G.N. Lu, V. Aimeza, P.G. Charrette, "Integration of hybrid optical filter with buried quad pnjunction photo detector for multi-labeling fluorescence detection applications”, DTIP, pp. 300-304, May 2011.

[24] C. Richard, T. Courcier, P. Pittet, S. Martel, L. Ouellet, G.N. Lu, V. Aimez, P.G. Charette, "CMOS buried Quad p-n junction photodetector for multi-wavelength analysis", OSA, Optics Express, vol. 20, no. 3, pp. 2053-2061, January 2012.

[25] T. Courcier, M. Goularta, P. Pittet, D.W. de Lima Monteiro, P.G. Charette, V. Aimez, G.N. Lu, "CMOS BQJ detector chip with integrated charge-amplifiers for fluorescence measurements", Elsevier, Sensors and Actuators B: Chemical, vol. 190, pp. 288-294, January 2014.

[26] T. Courcier, P. Pittet, P.G. Charette, V. Aimez, G.N. Lu, "BQJ Photodetector Signal Processing”, IC-MAST, Prague, Czech Republic, September 2013. Proc. in Trans Tech Publications, Key Engineering Materials, vol. 605, pp. 91-94, April 2014.

[27] S. Feruglio, T. Courcier, A. Karami, A. Alexandre-Gauthier, O. Romain, V. Aimez, P.G. Charette, P. Pittet, G.N. Lu, "Opto-electrical Modeling of CMOS Buried Quad Junction Photodetector", IC-MAST, Prague, Czech Republic, September 2013. Proc. In Trans Tech Publications, Key Engineering Materials, vol. 605, pp. 470-473, April 2014.

[28] G.N. Lu, T. Courcier, B. Mamdy, S. Feruglio, P.G. Charette, V. Aimez, O. Romain, P. Pittet, "CMOS buried multi-junction (BMJ) detector for bio-chemical analysis", SPIE, AOPC, Beijing, China, pages 1-6, May 2015.

[29] N.M. Matos Pires, T. Dong, U. Hanke, N. Hoivik, "Recent Developments in Optical Detection Technologies in Lab-on-a-Chip Devices for Biosensing Applications", MDPI, Sensors, vol. 14, pp. 15458-15479, August 2014.

[30] A.T. Pereira, P. Novo, D.M.F Prazeres, V. Chu, J.P. Conde JP, "Heterogeneous immunoassays in microfluidic format using fluorescence detection with integrated amorphous silicon photodiodes", AIP, Biomicrofluidics, vol. 5, no. 1, 014102, March 2012.

[31] E. Kamrani, F. Lesage, M. Sawan, "Low-Noise, High-Gain TIA Integrated with CMOS APD for Low-Intensity Light Detection in NearInfrared Spectroscopy", IEEE, Sensors Journal, vol. 14, issue 1, pp. 258-269, January 2014.

[32] A. Kolar, A. Pinna, O. Romain, S. Viateur, T. Ea, E. Belhaire, T. Graba, B. Granado, "A Multishutter Time Sensor for Multispectral Imaging in a 3-D Reconstruction Integrated Sensor", IEEE, Sensors Journal, vol. 9, issue 4, pp. 478-484, April 2009.

[33] A. Tournier, G.N. Lu, F. Roy, B. Deschamps, "A 2.2- $\mu$ m-Pitch SingleTransistor Charge-Modulation Pixel in a $0.13-\mu \mathrm{m}$ CMOS Process", IEEE, Transactions on Electron Devices, vol. 54, issue 10, pp. 26232629, October 2007.

[34] E.A.G. Webster, R.J. Walker, R.K. Henderson, L.A. Grant, “A silicon photomultiplier with $>30 \%$ detection efficiency from $450-750 \mathrm{~nm}$ and $11.6 \mu \mathrm{m}$ pitch NMOS-only pixel with $21.6 \%$ fill factor in $130 \mathrm{~nm}$ CMOS", Proc. of IEEE ESSDERC, pp. 238-241, September 2012.

[35] S.M. Sze, "Physic of Semiconductor Devices", ed. J. Wiley \& Sons, New York, 1981.
[36] B. Harbecke, "Coherent and incoherent reflection and transmission of multilayer structures", Springer, Applied Physics B-lasers and Optics, vol. 39, no. 3, pp. 165-170, March 1986.

[37] O.S. Heavens, "Optical Properties of Thin Films", ed. Dover Publications, New York, 1965.

[38] P.E. Schmid, "Optical absorption in heavily doped silicon", APS, Physical Review B, vol. 23, issue 10, pp. 5531-5536, May 1981.

[39] J. Geist, A. Migdall, H.P. Baites, "Analytic representation of the silicon absorption coefficient in the indirect transition region", OSA, Applied Optics, vol. 27, issue 18, pp. 3777-3779, September 1988.

[40] ASTM F28-91, Annual Book of ASTM Standards, vol. 10.05, Philadelphia, 1993.

[41] B. Senapati, S. Klinger, V. Vescoli, E. Seebacher, M. Berroth, "A SPICE Model for Silicon Photodiode", MOS-AK, Munich, Germany, September 2007.

[42] G. Peng, C HongDa, M. Luhong, "Behavior model of a CMOS process compatible photo-diode", IEEE International Conference on Group IV Photonics, Hong-Kong, China, pp. 110-112, September-October 2004.

[43] R.J. Perry, K. Arora, "Using PSPICE to simulate the photoresponse of ideal CMOS integrated circuit photodiodes" Proc. IEEE Southeastcon, Tampa, Florida, USA, pp. 374-380, April 1996.

[44] L. Ravezzi, G.F. Dalla Betta, D. Stoppa, A. Simoni, "A versatile photodiode SPICE model for optical microsystem simulation", Elsevier, Microelectronics Journal, vol. 31, issue 4, pp. 277-282, April 2000.

[45] Z. Huiming, Zeng, T. Wei, R. Zheng, "Modeling of pinned photodiode for CMOS image sensor”, IEEE ICSPCC, Xi' An, Shaanxi, China, pp. 14, September 2011.

[46] J. Bian, X. Chen, C. Chen, "A Novel Spice Model of Photodetector for OEIC Design”, Proc. of SPIE, China, vol. 6621, pp. 66211E.166211E.8, March 2008.

[47] Hamamatsu corp, Physical Technical Information, http://www.physics.ucc.ie/fpetersweb/FrankWeb/courses/PY3108/Labs/ PD_Info.pdf.

[48] J. Baker, "CMOS: Circuit Design, Layout, and Simulation", 3rd Edition, ed. Wiley-IEEE Press, New York, 2010.

[49] D.K. Schroder, "Carrier Lifetimes in Silicon", IEEE, Transaction on Electron Devices, vol. 44, issue 1, pp. 160-170, January 1997.

[50] G.A.M. Hurkx, H.C. de Graaff, W.J. Kloosterman, M.P.G Knuvers, “A new analytical diode model including tunneling and avalanche breakdown", IEEE, Transactions on Electron Devices, vol. 39, issue 9, pp. 2090-2098, August 1992.

[51] J.P. Carrere, S. Place, J.P. Oddou, D. Benoit, F. Roy, "CMOS image sensor: Process impact on dark current", IEEE IRPS, Waikoloa, HI, pp. 3C.1.1-3C.1.6, June 2014.

[52] L. Quiquerez, S. Ouaaziz, P. Pittet, G. N. Lu, "A VHDL-AMS package for microsystems polychromatic optical modeling”, Proc. SPIE, Strasbourg, France, vol. 5455, pp. 364-374, August 2004.

[53] Synopsis, "Taurus - Medici User Guide", version V-2003.12, 2003.

[54] Synopsis, "Sentaurus Device User Guide", version D-2010.03, 2010.

[55] K. Rajkanan, R. Singh, J. Shewchun, "Absorption Coefficient of Silicon for Solar Cell Calculations”, Elseivier, Solid-State Electronics, vol. 22, no. 9, pp. 793-795, September 1979.

Sylvain Feruglio (M'06) received the B.Sc. and M.Sc. degrees in electronic, electrotechnic, and automatism and the master's degree in electronics, option instrumentation, and systems from the Université Pierre et Marie Curie (UPMC) - Paris 6, Sorbonne Université (France), in 1999, 2000, and 2001, respectively, and the Ph.D. degree in noise computation in integrated active pixel image sensors from LISIF, UPMC, in 2005. He continues his activities through a postdoctoral position with IMEP-LAHC, Institut National Polytechnique de Grenoble (France), which concerns the study and the characterization of new CMOS and SOI technologies. Since 2007, he is currently with LIP6 in the System on Chip department. His research interests include integrated sensors and electronics, noise analysis and signal integrity, mainly applied to image sensors and biomedical engineering. 
T. Courcier obtained his Ing. degree in electronics and automatism in 2005, a master's degree in micro and nanotechnology in 2010 from Université Joseph Fourier (Grenoble, France) and his Ph.D. in Electrical Engineering in 2014 from both Université Claude Bernard Lyon 1 (Lyon, France) and Université de Sherbrooke (Sherbrooke, Canada).

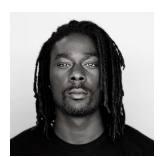

O. Tsiakaka (M'15) received the B.Sc. degree in electronic engineering and the M.Sc. degree in electrical and computer engineering, respectively in 2012 and 2014, from UPMC, where he is currently working toward the Ph.D. degree in LIP6. His researches mainly include biomedical engineering and instrumentation.

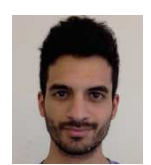

A. Karami (M'15) received the M.Sc. degree in electrical engineering from UPMC in 2014. He is currently pursuing a Ph.D. degree at LIP6. His $\mathrm{Ph} . \mathrm{D}$. research is focused on the theory, conception and analysis of CMOS and MEMS circuits, mainly on the conditioning circuits for vibration energy harvesting.

A. Alexandre-Gauthier received her engineering degree from the Ecole Centrale de Lyon and his master's degree "devices of the integrated electronics" in 1986. She obtained her $\mathrm{PhD}$ degree on "Development and software implementation of a model for the two-dimensional numerical simulation of the injection of hot carriers in electronic components" in January 1990. Since September 1990, she was an Associated Professor at UPMC in LIP6. Her research interests mainly include modeling and simulation in integrated CMOS devices, image sensors and biomedical engineering.

O. Romain (M'12) holds an engineering degree from ENS Cachan (France), M.Sc. from Université Louis Pasteur University (Strasbourg, France), and Ph.D. from UPMC, all in Electronics. Since 2012, he is head of the architecture department at ETIS laboratory. $\mathrm{He}$ is full professor of electrical engineering at Université de Cergy-Pontoise (France). His research interests are in system on chip for broadcast and biomedical applications.

V. Aimez obtained his Ph.D. in Electrical Engineering in 2000 from the Universite de Sherbrooke (Canada). He is currently Professor in the Department of Electrical and Computer Engineering at Université de Sherbrooke and the Director of Scientific Partnerships with the MiQro Innovation Collaborative Center (Bromont, Canada).

P.G. Charrette obtained his Ph.D. in Biomedical Engineering in 1986 from McGill University (Montréal, Canada). He is currently Professor in the Department of Electrical and Computer Engineering at Université de Sherbrooke (Canada).

P. Pittet was graduated in Electronic Engineering from CPELyon in 1990 and obtained his Ph.D. degree from UCBL Université Lyon 1 (Villeurbanne, France). He is currently Research Engineer at INL - Université Lyon 1.
G.N. Lu received the B.Sc. degree from the South-China University of Technology, Guangdong, in 1981, and the M.Sc. degree from the Central Engineering School of Lyon (France) in 1984, and the Ph.D. degree from the University Paris 11, in 1986. From 1988 to 1999 , he was an associate professor at the University Paris 7. Since 1999, he has been a professor of electrical engineering at INL - University Lyon 1. His current research interests include semiconductor devices, integrated sensors and associated electronics. 